\title{
To What Degree is the Fourth Industrial Revolution an Opportunity or a Threat for the ASEAN Community and Region?
}

\author{
Weng Marc $\operatorname{Lim}^{1}$ \\ ${ }^{1}$ Head of School, School of Business, Swinburne University of Technology, Sarawak, Malaysia \\ Correspondence: Weng Marc Lim, Head of School, School of Business, Swinburne University of Technology, \\ Sarawak, Malaysia. E-mail: lim@wengmarc.com / marclim@swin.edu.au / wlim@swinburne.edu.my
}

Received: August 12, 2019

Accepted: August 27, 2019

Online Published: August 28, 2019

doi:10.5539/mas.v13n9p105

URL: https://doi.org/10.5539/mas.v13n9p105

\begin{abstract}
This article aims to offer a brief and quick dissemination on the potential impacts - in the form of opportunities and threats - of the Fourth Industrial Revolution on the ASEAN region. It is in line with one of the programme pillars of the World Economic Forum on ASEAN, specifically ASEAN and the connectivity agenda. The author hopes that this article will stimulate further dialogues and investigations on how the ASEAN community can capitalize and leverage on the inherent opportunities and avoid and overcome the underlying threats arising from the Fourth Industrial Revolution.
\end{abstract}

Keywords: ASEAN, Fourth Industrial Revolution, opportunities, threats, World Economic Forum

\section{Introduction}

The world's first industrial revolution (i.e. driven by mechanization) began 250 years ago. Fast forward to today, the world, after two further industrial ages (i.e. the second and third, which were driven by mass production and automation, respectively), is on the verge of a new era of industrial revolution (i.e. the fourth, which will be driven by connectivity), and thus calling for greater scrutiny and understanding about its impact on socioeconomic activities around the world (World Economic Forum, 2016). Of particular interest herein is the opportunities and threats that the Fourth Industrial Revolution will produce for the ASEAN community (i.e. Brunei, Cambodia, Indonesia, Laos, Malaysia, Myanmar, Philippines, Singapore, Thailand, and Vietnam).

\section{ASEAN as a Community and a Region}

Since its inception 50 years ago (i.e. 1967), ASEAN has grown into one of the world's most dynamic regions with accelerated socioeconomic performance in recent years. The region has a combined population of over 600 million, and thus establishing itself as Asia's third and the world's seventh largest market (ASEAN, 2019). Notwithstanding its global standings, which are attributable to cooperation and integration initiatives that have taken concrete shape over the past two decades (e.g. framework agreements on free trade areas, services, goods, and investment in 1992, 1995, 2010, and 2012 respectively), the ASEAN community continues to deal with the issue of socioeconomic disparity, which is attributable to poor and inequitable conditions, such as low capital budgets and limited access to higher-level education opportunities, among others.

\section{Opportunities Brought by the Fourth Industrial Revolution for the ASEAN Community and Region}

The concentration on connectivity, spearheaded and supported by the advancement of digital technologies (e.g. big data, internet of things), in the Fourth Industrial Revolution can create opportunities to tackle some of the most pressing issues about socioeconomic inequality in ASEAN (Baller et al., 2016; Schwab, 2017). More specifically, greater connectivity allows greater accessibility and pooling of scarce monetary (e.g. money) and non-monetary (e.g. effort, time, talent) resources, which can be facilitated through crowd and cloud systems. This, in turn, creates an array of alternatives to address socioeconomic disparity issues, such as to overcome the limitations of self-reliant capital budgets and to improve accessibility to public service (e.g. higher-level education), in ASEAN. Moreover, greater connectivity enables greater reduction in or elimination of redundant practices, such as by breaking down silo practices that lead to duplication in investment and utilization of scarce resources to solve identical or similar problems (e.g. community empowerment, population health). This, in turn, engineers recalibration of attention and focus among countries in the ASEAN community to develop new 
solutions for socioeconomic problems that remain unattended or for enhancement and novelty in socioeconomic areas that remain unexplored or underexplored in the broader community.

\section{Challenges Brought by the Fourth Industrial Revolution for the ASEAN Community and Region}

Nonetheless, the focus on connectivity in the Fourth Industrial Revolution can also produce threats that worsen some of the long-standing issues about socioeconomic disparity in the ASEAN community. More specifically, the increased accessibility to communities that face socioeconomic inequalities facilitated through enduring efforts for greater connectivity can motivate elite sectors in more advanced ASEAN economies to leverage on their specialized knowledge and skills to develop and own technologies that place others in less advanced ASEAN economies in a captive (rather than an empowered) position due to the potential to reap the lucrative rewards (e.g. customer dollars) characterizing larger-sized markets, and thus leading to superior polarization in the form of a winner-takes-all economy (as in the case of the West vs. the East). An oxymoron to this can also occur when such accessibility moves in the opposite direction where the concentration on connectivity turns specializations of independent ASEAN countries into commodities for the collective ASEAN community, specifically when what was previously considered a rarity due to restricted access has become common as a result of dissolving boundaries in networked communities (e.g. skilled labor). Moreover, the possibility of local culture deterioration cannot be discounted as greater connectivity exposes previously disparate ASEAN communities to a global lifestyle and working culture, thereby shaping contemporary attitudes, beliefs, values, and behaviors required to operate in a borderless regional environment.

\section{Conclusion}

In short, a network of communities that are easily accessible to each other can bring about great possibilities for progress, but at the same time poses notable threats to the realization of that progress, especially for the ASEAN community in the era of the Fourth Industrial Revolution. Further dialogues and investigations are necessary on how the ASEAN community can capitalize and leverage on the inherent opportunities and avoid and overcome the underlying threats created by the Fourth Industrial Revolution, starting with the World Economic Forum on ASEAN.

\section{References}

ASEAN. (2019). ASEAN Economic Community. Available at https://asean.org/asean-economic-community/

Baller, S., Dutta, S. \& Lanvin, B. (2016). The global information technology report. Geneva: World Economic Forum.

Schwab, K. (2017). The fourth industrial revolution. London: Penguin UK.

World Economic Forum. (2016). The fourth industrial revolution: What it means, how to respond. Available at https://www.weforum.org/agenda/2016/01/the-fourth-industrial-revolution-what-it- means-and-how-to respond/

\section{Copyrights}

Copyright for this article is retained by the author(s), with first publication rights granted to the journal.

This is an open-access article distributed under the terms and conditions of the Creative Commons Attribution license (http://creativecommons.org/licenses/by/4.0/). 